KueCZkowski, J. AND KLECZKowski, A. (1954). J. gen. Microbiol. 11, 451-458.

\title{
The Effect of Ribonuclease on Phage-Host Interaction
}

\author{
By J. KLECZKOWSKI AND A. KLECZKOWSKI \\ Rothamsted Experimental Station, Harpenden, Hertfordshire
}

SUMMARY: Pancreatic ribonuclease inhibits the multiplication of a Rhizobium bacteriophage in liquid bacterial cultures by preventing permanent combination between phage and host. The addition of ribonuclease after phage has already combined with the bacteria does not prevent phage from multiplying, but it does decrease the rate of multiplication; the enzyme also interferes with multiplication of the bacteria. Experiments with ribonuclease in conjunction with chymotrypsin suggest that phage and bacteria unite in the presence of ribonuclease but that the union is only transitory and ends by the release of still active phage. In the presence of chymotrypsin, however, the phage becomes inactive during this transient union.

The multiplication of a Rhizobium bacteriophage in liquid culture of its host bacterium is inhibited by both ribonuclease and chymotrypsin, although neither enzyme affects plaque formation on agar media (Kleczkowski \& Kleczkowski, 1952, 1954). Nor do they affect the bacteriophage when mixed with it in the absence of its host. But the fact that ribonuclease inhibits the multiplication of the host cells, whereas chymotrypsin does not suggested that they might inhibit phage multiplication by different mechanisms. Chymotrypsin does not affect the combination between phage and bacteria, but affects a transient stage in the infection process occurring after combination, for if chymotrypsin is added $1 \mathrm{~min}$. after the combination, infection and phage multiplication proceed normally (Kleczkowski \& Kleczkowski, 1954). The work described in the present paper was done to find the stage or stages of the infection process modified by ribonuclease alone or in conjunction with chymotrypsin.

\section{METHODS}

Methods and materials were similar to those used previously (Kleczkowski \& Kleczkowski, 1952, 1954). Ribonuclease, crystallized by the method of Kunitz (1940), was dissolved in $0.067 \mathrm{M}$-phosphate buffer $(\mathrm{pH} 7 \cdot 2)$ and heated for $5 \mathrm{~min}$. in a boiling water-bath. Any coagulum that appeared was removed by centrifugation. The results with a series of different unheated preparations were inconsistent, probably because the preparations contained different amounts of materials affecting the inhibition by ribonuclease of phage/host interaction. One such material is a proteolytic enzyme, and there may be others; heating under the above conditions destroys proteolytic activity without greatly impairing the ribonuclease activity (Kleczkowski, 1948).

\section{RESULTS}

Effect of ribonuclease on the interaction between phage and live bacteria

Table 1 shows that the presence of $0.1 \%$ ribonuclease in a phage + bacteria mixture prevented phage multiplication during the first $3 \mathrm{hr}$. of incubation 
and greatly slowed it during $24 \mathrm{hr}$. (test no. 1). Like chymotrypsin, it had no apparent effect on the phage alone (test no. 3).

To test whether the ability of bacteria to interact with phage is altered by ribonuclease, bacterial cultures were incubated with $0.1 \%$ ribonuclease for $3 \mathrm{hr}$. at $25^{\circ}$. The bacteria were then centrifuged down, suspended in fresh medium and phage added (test no. 5). The incubated bacteria did not support normal phage multiplication, although multiplication was less inhibited than when the medium contained ribonuclease (test no. 1). This result contrasts with that obtained when bacteria were incubated with chymotrypsin (Kleczkowski \& Kleczkowski, 1954), for after removing chymotrypsin the bacteria interacted normally with the bacteriophage.

Table 2 shows that the presence of $0.1 \%$ ribonuclease almost entirely prevented phage from combining with the bacteria, in conditions when without it about $90 \%$ of the phage combined. Also, when phage was added to bacteria which had previously been incubated for $3 \mathrm{hr}$. with $0.1 \%$ ribonuclease and then sedimented by centrifugation and re-suspended in fresh medium, only about $50 \%$ of the phage combined with the bacteria so treated. This result also contrasts with that obtained with chymotrypsin which does not affect the combination between phage and its host bacterium (Kleczkowski \& Kleczkowski, 1954).

Table 3 shows that incubation of the bacteria alone for $1 \mathrm{hr}$. in presence of $0.1 \%$ ribonuclease made about $70 \%$ of them unable to form colonies (compare tests nos. 1 and 2, Table 3 ). By contrast, as ribonuclease protects the bacteria from lysis by phage, 4 times as many bacteria formed colonies after incubation with phage + ribonuclease as after incubation with phage alone (tests nos. 3 and 4). Ribonuclease can therefore alter the bacteria enough to make them unable to multiply, and effects less drastic than this might suffice to make normal interaction with bacteriophage impossible and so protect bacteria from phage. These results with ribonuclease are again in contrast with those previously obtained with chymotrypsin which protects bacteria from lysis by phage without detectably affecting bacterial multiplication (Kleczkowski \& Kleczkowski, 1954).

Ribonuclease might prevent combination between phage and bacteria because it affects a ribonucleic acid situated on the bacterial surface, possibly the ribonucleic acid which Harris (1953) found to be removed by ribonuclease from heat-killed bacteria. However, the effect of ribonuclease may not be enzymic but may be caused by electrostatic combination of the enzyme with a component of the bacterial surface.

To test whether ribonuclease affects the interaction between phage and bacteria after they have combined, the enzyme was added to a phage + bacteria mixture after it had been incubated at $25^{\circ}$ for half an hour, by which time about $80 \%$ of phage had combined with bacteria. After $3 \mathrm{hr}$. more incubation the concentration of phage (assayed by plaque count) increased to about $60 \%$ of the concentration expected if all the combined phage had multiplied normally. Obviously ribonuclease did not prevent the phage already combined with bacteria from multiplying. There are three possible reasons for the slight 
Phage-host interaction

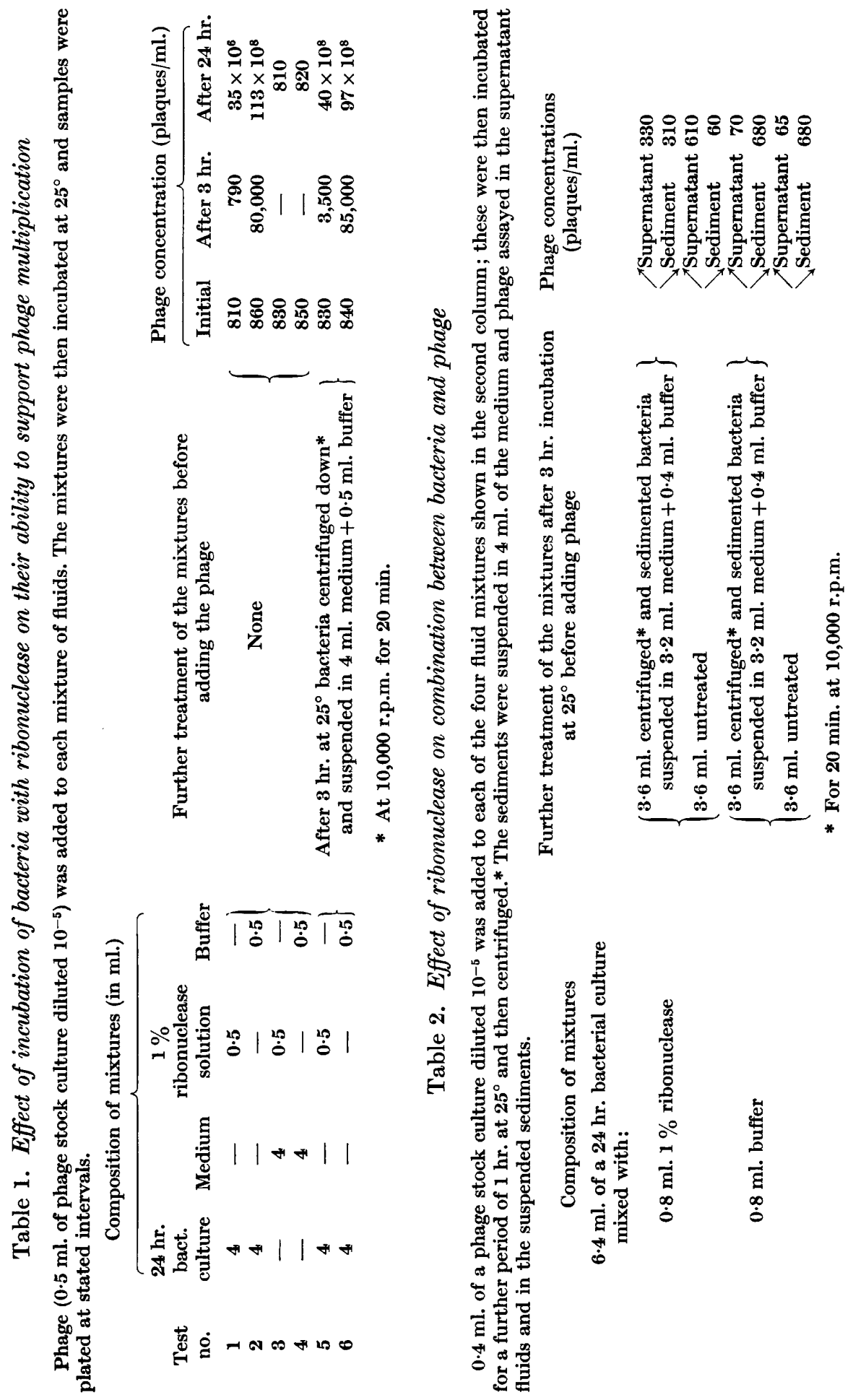


decrease in the yield obtained after $3 \mathrm{hr}$. incubation: the first is a decrease in the numbers of phage particles produced by individual cells; the second, an extension of the latent period and/or of the period of release of phage from bacteria, which normally take together about $3 \mathrm{hr}$. (Kleczkowski \& Kleczkowski, 1954); the third, prevention of phage multiplication in some cells. The last possibility seems the least likely because the whole culture ultimately lysed.

Table 3. Effect of ribonuclease on the ability of bacterial cells to multiply and form colonies

The mixtures were incubated for $1 \mathrm{hr}$. at $25^{\circ}$, then diluted $10^{-5}, 1 \mathrm{ml}$. samples of the diluted fluids mixed with $9 \mathrm{ml}$. of $0.7 \%$ agar medium (which was previously melted and cooled to $42^{\circ}$ ) and poured into Petri dishes. Bacterial colonies were counted after 5 days at $25^{\circ}$.

\begin{tabular}{|c|c|c|c|c|c|}
\hline \multirow[b]{2}{*}{ Test no. } & \multicolumn{4}{|c|}{$\begin{array}{l}\text { Composition of mixtures (in ml.) } \\
2 \mathrm{ml} \text {. of a } 24 \mathrm{hr} \text {. bacterial culture }+\end{array}$} & \multirow[b]{2}{*}{$\begin{array}{c}\text { Number of } \\
\text { colonies/plate } \\
\text { (mean of } 3 \text { plates) }\end{array}$} \\
\hline & $\begin{array}{c}1 \% \\
\begin{array}{c}1 \% \text { ribonuclease } \\
\text { solution }\end{array}\end{array}$ & Buffer & $\begin{array}{l}\text { Phage stock } \\
\text { culture } \\
\text { (undil.) }\end{array}$ & $\begin{array}{l}\text { Culture } \\
\text { medium }\end{array}$ & \\
\hline 1 & 0.5 & - & - & 2 & 30 \\
\hline 2 & - & 0.5 & - & 2 & 100 \\
\hline $\mathbf{3}$ & 0.5 & - & 2 & - & 20 \\
\hline 4 & - & 0.5 & 2 & - & 5 \\
\hline
\end{tabular}

Joint effect of ribonuclease and chymotrypsin on the interaction between phage and live bacteria

The joint action of ribonuclease and chymotrypsin on the interaction between phage and host was examined for two reasons: first, to see whether ribonuclease, by preventing phage and host from combining, protects the phage from being inactivated by chymotrypsin, which seems able to inactivate only after phage has combined with its host; secondly, observations on such mixtures provide a method of seeing whether ribonuclease separates phage from bacteria with which it has already combined. There seemed no method of doing this directly, because of the short period between combination and irreversible infection, whereas what is known of the action of chymotrypsin suggested it might prolong this period sufficiently to test whether ribonuclease can separate the two and permit recovery of free phage.

Table 4 shows that the addition of ribonuclease before or immediately after adding chymotrypsin to bacteria which were then mixed with phage, only slightly decreased the rate at which chymotrypsin inactivated the phage (cf. test nos. 2, 4 and 5, Table 4). Table 4 also shows that adding ribonuclease $3 \mathrm{hr}$. after mixing chymotrypsin, phage and bacteria did not affect the concentration of residual phage (cf. test nos. 2 and 6, Table 4). Thus, ribonuclease neither prevented phage and bacteria from combining nor separated any active phage that had already combined.

At first sight the results of the experiments using the two enzymes together seem to conflict with those where each was used separately. There is good evidence that chymotrypsin acts by inactivating phage which is combined 


\section{Phage-host interaction}

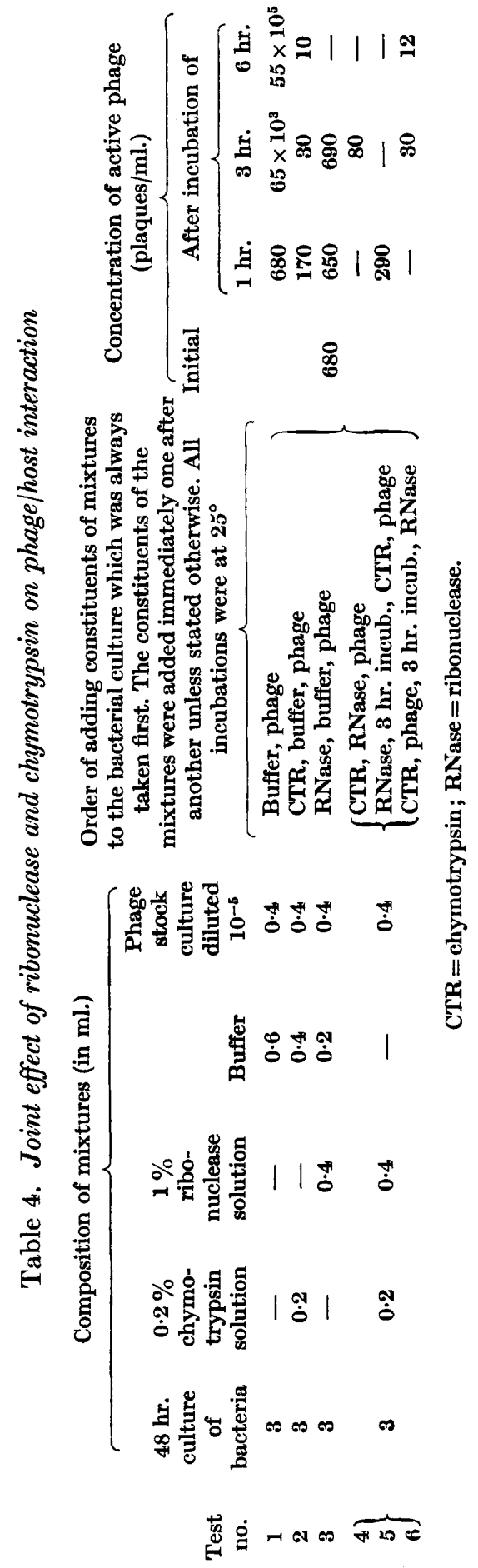


with bacteria but has no effect on free phage (Kleczkowski \& Kleczkowski, 1954). When ribonuclease was used alone (Table 2) there was also evidence that normal combination between bacteria and phage did not occur. Yet when chymotrypsin and ribonuclease are present together chymotrypsin still had its usual inactivating action. The most reasonable interpretation of these facts seems to be that in the presence of ribonuclease phage and bacteria do combine, and that during this phase the phage can be inactivated by chymotrypsin; unless chymotrypsin is present the combination is only transitory, and phage and bacteria separate before infection occurs. Alternative explanations for the results with the two enzymes together would be that chymotrypsin affects: (i) ribonuclease so that it does not have its usual action in preventing phage and bacteria from combining; or (ii) the bacteria so that ribonuclease no longer acts on them in a way that can prevent combination with phage. However, neither of these explanations seems very probable. Although chymotrypsin can hydrolyse ribonuclease (Kleczkowski, 1948), it does so very slowly, and in the conditions of these experiments the amount hydrolysed would be insignificant. Also, chymotrypsin does not remove from the bacteria the substance on which ribonuclease acts, because this is needed for infection between phage and bacteria and infection occurs normally after bacteria have been incubated with chymotrypsin.

The conclusion is that, in the presence of ribonuclease, phage and bacteria combine, but that the combination is broken up before infection occurs or the phage has been permanently altered. A bacterial ribonucleic acid which is not concerned with the initial combination between phage and bacterium, might be essential to some second step that makes combination irreversible. The hydrolysis of this ribonucleic acid by ribonuclease would prevent newly combined phage from being 'fixed' to the bacterial surface so that the combination could be transitory and apparently unaltered phage set free again. Chymotrypsin inactivates the phage during the transitory combination when the 'fixation' is prevented by ribonuclease. Susceptibility to the inactivating effect of chymotrypsin is not, therefore, caused by any major change of the phage particle, such as separation of its protein from its nucleic acid (Hershey $\&$ Chase, 1952). Whether the moment when normally combined phage ceases to be susceptible to chymotrypsin coincides with such a major change is unknown, likewise what susceptibility to chymotrypsin means. Active phage is lost, but this could occur for a variety of reasons ranging from destruction of phage particles to their becoming cemented to bacteria. It is not clear whether the period of combination before 'fixation' is equivalent to the reversible combination described by Garen \& Puck (1951) with coli phages. Their phages and hosts were separable only when the ionic content of the medium was made unsuitable for combination, whereas combination of the Rhizobium phage with host in the presence of ribonuclease is reversible in media otherwise favourable for infection. 
Phage-host interaction

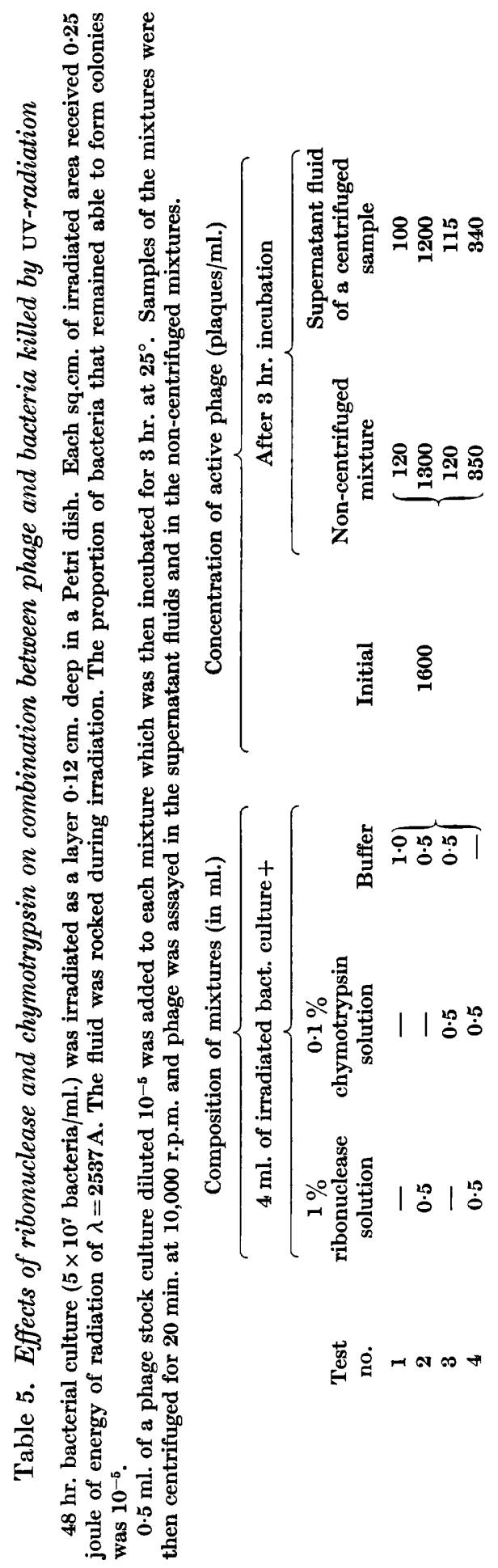




\section{Effects of ribonuclease and chymotrypsin on the interaction between phage and bacteria killed by ultraviolet radiation}

Bacteria killed by ultraviolet (UV) radiation can still combine specifically with phage, but how far the normal stages of infection proceed is unknown. Tests were therefore made to compare the effects of ribonuclease and chymotrypsin on the combination of phage with uv-killed bacteria and live bacteria. Tests were also made to see whether phage combined with uv-killed bacteria could later be separated by ribonuclease.

Table 5 shows that the concentration of active phage decreased in the presence of the killed bacteria and remained unaffected when the bacteria were centrifuged out (test no. 1, Table 5). Evidently the phage that was combined with the killed bacteria could not infect live bacteria. The presence of ribonuclease prevented permanent combination of phage with the killed bacteria (test no. 2). Chymotrypsin alone had no effect on the combination (test no. 3), but when present together with ribonuclease, it counteracted the effect of the latter so that the concentration of active phage decreased at a rate only slightly smaller than in the absence of ribonuclease (test no. 4). Separate and joint effects of the two enzymes on combination of phage with Uv-killed bacteria were the same as with live bacteria, so it seems reasonable to conclude that the mechanism of interaction of phage with uv-killed bacteria is identical with that of early stages of its interaction with live bacteria.

Addition of ribonuclease to mixtures of phage + killed bacteria which had been incubated together for $3 \mathrm{hr}$. at $25^{\circ}$, did not liberate any active phage, but it prevented the combination of any further phage. The inability of ribonuclease to liberate 'fixed' phage suggests that the interaction between phage and uv-killed bacteria may go beyond the stage of 'fixation'.

\section{REFERENCES}

Garen, A. \& Puck, T. T. (1951). The first two steps of the invasion of host cells by bacterial viruses. J. exp. Med. 94, 177.

HARRIS, J. O. (1953). Electrophoretic behaviour and crystal violet adsorption capacity of ribonuclease treated bacterial cells. J. Bact. $65,518$.

Hershey, A. D. \& Chase, M. (1952). Independent functions of viral protein and nucleic acid in growth of bacteriophage. J. gen. Physiol. 36, 39.

KLeczkowskI, A. (1948). Proteolytic activity of preparations of crystallized ribonuclease. Biochem. $J .42,523$.

KLeczkowSKI, J. \& KLECzKowski, A. (1952). Effect of specific polysaccharides from host bacteria and of ribonuclease on the multiplication of Rhizobium phages. J. gen. Microbiol. 7, 340.

KLeCZkOWSKI, J. \& KLeCzKowski, A. (1954). A study of the mechanism of inhibition of bacteriophage multiplication by chymotrypsin. J. gen. Microbiol. 10, 285.

Kunitz, M. (1940). Crystalline ribonuclease. J. gen. Physiol. 24, 15. 